\title{
ElectroChemical Arsenic Removal (ECAR) for Rural Bangladesh - Merging Technology with Sustainable Implementation
}

\author{
Susan E.A. Addy ${ }^{1,2}$, Ashok J. Gadgil ${ }^{1,2}$, \\ Kristin Kowolik $^{1,2}$, Robert Kostecki ${ }^{2}$ \\ ${ }^{1}$ University of California, Berkeley \\ Department of Civil and Environmental Engineering \\ Berkeley, CA, 94720 \\ ${ }^{2}$ Environmental Energy Technologies Division \\ Indoor Environment Department \\ Lawrence Berkeley National Laboratory \\ Berkeley, CA, 94720
}

December 2009

This work was conducted at the University of California and Lawrence Berkeley National Laboratory under U.S. Department of Energy Contract No. DE-AC02-05CH11231.

Funders include the US EPA Phase I and II Award, the National Collegiate Inventors and Innovators Alliance (NCIIA), Berkeley's Richard C. Blum Center for Developing Economies, Bears Breaking Boundaries Contest, sustainable Products and Solutions Program, and Big Ideas Marketplace. 


\title{
ElectroChemical Arsenic Removal (ECAR) for Rural Bangladesh - Merging Technology with Sustainable Implementation
}

\author{
Susan E.A. Addy ${ }^{1,2}$, Ashok J. Gadgil ${ }^{1,2}$, Kristin Kowolik ${ }^{1,2}$, and Robert Kostecki ${ }^{2}$ \\ ${ }^{1}$ University of California, Berkeley, CA, 94720 \\ ${ }^{2}$ EETD, Lawrence Berkeley National Laboratory, Berkeley, CA, 94720 \\ Corresponding author: Susan E.A. Addy, Department of Civil and Environmental Engineering, UC \\ Berkeley, 760 Davis Hall, Berkeley, CA 94720-1710; susan.e.addy@gmail.com
}

This report is an improved version of the paper published in the proceedings of: The 2008 University of North Carolina Environmental Symposium: Safe and Sustainable Drinking Water in Developing Countries: Where Science Meets Policy, Chapel Hill, NC, November 5-6 2008.

\section{Abstract}

Today, 35-77 million Bangladeshis drink arsenic-contaminated groundwater from shallow tube wells. Arsenic remediation efforts have focused on the development and dissemination of household filters that frequently fall into disuse due to the amount of attention and maintenance that they require. A community scale clean water center has many advantages over household filters and allows for both chemical and electricity-based technologies to be beneficial to rural areas. Full cost recovery would enable the treatment center to be sustainable over time. ElectroChemical Arsenic Remediation (ECAR) is compatible with community scale water treatment for rural Bangladesh. We demonstrate the ability of ECAR to reduce arsenic levels $>500 \mathrm{ppb}$ to less than $10 \mathrm{ppb}$ in synthetic and real Bangladesh groundwater samples and examine the influence of several operating parameters on arsenic removal effectiveness. Operating cost and waste estimates are provided. Policy implication recommendations that encourage sustainable community treatment centers are discussed.

This work was conducted at the University of California and Lawrence Berkeley National Laboratory under U.S. Department of Energy Contract No. DE-AC02-05CH11231. Funders include the US EPA Phase I and II Award, the National Collegiate Inventors and Innovators Alliance (NCIIA), Berkeley's Richard C. Blum Center for Developing Economies, Bears Breaking Boundaries Contest, Sustainable Products and Solutions Program, and Big Ideas Marketplace. 


\section{DISCLAIMER}

This document was prepared as an account of work sponsored by the United States Government. While this document is believed to contain correct information, neither the United States Government nor any agency thereof, nor The Regents of the University of California, nor any of their employees, makes any warranty, express or implied, or assumes any legal responsibility for the accuracy, completeness, or usefulness of any information, apparatus, product, or process disclosed, or represents that its use would not infringe privately owned rights. Reference herein to any specific commercial product, process, or service by its trade name, trademark, manufacturer, or otherwise, does not necessarily constitute or imply its endorsement, recommendation, or favoring by the United States Government or any agency thereof, or The Regents of the University of California. The views and opinions of authors expressed herein do not necessarily state or reflect those of the United States Government or any agency thereof or The Regents of the University of California. 


\section{Introduction}

Arsenic in drinking water is a major public health problem threatening the lives of over 140 million people worldwide (Beck, 2007; Kahn, 2007). Primary drinking water supplies are contaminated in Argentina, Chile, Mexico, China, Hungary, Cambodia, Vietnam, West Bengal (India), Bangladesh, and areas of the United States, and more contamination continues to be discovered. Bangladesh is the hardest hit, with 35 - 77 million of its citizens exposed to levels well above the World Health Organization's maximum recommended limit $(10 \mathrm{ppb})$. The sheer magnitude of the population exposed has lead the situation to aptly be called "the largest mass poisoning of a population in history" (Smith et al., 2000).

The health effects of arsenic poisoning vary widely in severity, from chronic fatigue to deadly cancers (Chowdhury et al., 2000). Symptoms have a latency period of 5 to 20 years, making early detection difficult. Poor nutrition, common in the midst of poverty, is known to exacerbate the toxic effects of arsenic, especially in children (Rahman et al., 2005). Increased health costs, loss of productivity and income, and social exclusion can be perilous to a family at subsistence-level living ${ }^{1}$.

There are two primary categories into which safe water approaches fall - switching to alternative arsenic-free water sources and remediation of arsenic contaminated sources. The former category includes installation of deep tube wells (which are more likely to be arsenic-free), treatment of surface waters (e.g. Pond Sand Filters or shallow dugwells), and rainwater harvesting. Arsenic remediation efforts have primarily focused on household filters for contaminated wells. Arsenic removal is often based on adsorption onto a relatively low-cost chemical sorbent added to the water, such as zero-valent iron, granular ferric hydroxide or activated alumina. Each safe water option varies in capital and recurring costs, levels of maintenance, water quality, water flow-rate, social acceptability and other external factors.

Of the arsenic-free sources, the installation of deep tube wells is a strong preference among users (Hoque et al., 2004). However, deep tube wells are expensive, are only feasible where deep arsenicfree aquifers exist, and must be installed properly to avoid cross-contamination from shallow aquifers. There is also concern that increased pumping from deep aquifers could draw arsenic in from shallow counterparts (Yu, 2003). Household based point-of-use (POU) filters have been plagued by high abandonment rates after a short time (Ahmad et al., 2003; Hoque et al., 2004; Vergara, 2007), due to difficult maintenance or operation, the amount of attention required for operation, and low cultural acceptability. In addition, chemical adsorbents used in filters have limited effectiveness in removing As(III), which makes up about 70-90\% of the total arsenic measured in Bangladeshi tube wells (Bhattacharya et al., 2002).

In light of the repeated problems with household filter adoption and the continuing prevalence of arsenic in drinking water in Bangladesh, researchers at LBNL have recognized the need to be innovative in both technology and implementation. This interdisciplinary approach has led to the development of an efficient, effective, and low cost electricity-based technology known as ElectroChemical Arsenic Remediation (ECAR) for rural Bangladesh. This technology has a number of advantages over chemical adsorbents (discussed below) along with some additional challenges, such as

\footnotetext{
${ }^{1}$ A companion article by Mathieu et al. (this volume) contains a more complete list of health effects and discussion of welfare costs.
} 
the need for electricity. Electricity-based technologies are less appropriate for household filters in rural areas with limited electricity access. However, when partnered with an appropriate community scale implementation scheme, electricity-based technologies such as ECAR can be viable and beneficial to rural areas.

In the following, we present background on ECAR technology as well as initial performance results in synthetic Bangladesh groundwater and real groundwater collected in Bangladesh. We explore the effect of several ECAR operating conditions on removal efficiency and discuss ways that these parameters might be used to optimize efficiency based on local water conditions. We also discuss the advantages, potential risks, and policy implications of one possible implementation scheme - a community clean water center operating under full cost recovery - that is compatible with ECAR technology in rural and potentially non-electrified areas.

\section{ECAR performance and parameter optimization}

\subsection{Background}

In ElectroChemical Arsenic Remediation (ECAR), electricity is used to continuously dissolve iron, forming a combination of corrosion products such as ferric hydroxides, oxyhydroxides, and oxides (i.e. rust). These products together form an electrochemically-generated adsorbent, or EGA, with a high affinity for arsenic. EGA is manufactured at the time of use, eliminating the need for a costly supply chain. In addition, electrochemical processes greatly enhance the arsenic removal capacity (i.e. arsenic removed per unit iron input) of ECAR relative to the chemical addition of ferric salts or metallic iron. This is due to (i) an increase in the rate of rust production (by factors of 10 to 100 over natural rusting rate of metallic iron), and (ii) the rapid electrochemical oxidation of As(III) to the more favorable As(V), which binds much more readily to iron-based adsorbents. Thus employing a small amount of electricity allows for a large increase in efficiency, lower operating costs and production of far less arsenic-laden waste than most chemical adsorbents. In addition, the electrodes are self-cleaning if current is alternated, reducing maintenance and eliminating the need to handle strong alkalies and corrosive acids for regeneration (required of activated alumina and other regenerative adsorbents).

ECAR treatment is closely related to electrocoagulation, which has been used to treat wastewater containing arsenic (Balasubramanian and Madhavan, 2001; Hansen et al., 2006), foodstuff (Chen et al., 2000), textile dyes (Vlyssides et al., 2000), and fluorine (Mameri et al., 1998) among others contaminants. Electrocoagulation has also been proposed to treat potable water containing arsenic (Chen, 2004; Holt et al., 2002; Pouet and Grasmick, 1995) and successfully tested in the lab using Indian tap water (Kumar et al., 2004) and in the field using groundwater from La Comarca, Mexico (Parga et al., 2005). ECAR differs from electrocoagulation by the addition of a post-electrolysis mixing stage in which the EGA is allowed to further interact with arsenic without continuous generation. This allows for some increased arsenic removal without consuming additional iron or electricity, improving the efficiency of ECAR.

ECAR treatment is controlled by several operating parameters that could potentially be tuned to local water conditions to maximize arsenic removal capacity. These parameters include current density and charge density.

Current density is the operating current divided by the active surface area of the electrode (in $\mathrm{mA} / \mathrm{cm}^{2}$ ). It affects the composition of corrosion products making up EGA. Different corrosion products may 
have different affinities for arsenic, and the ability to control the composition of EGA allows for tuning to achieve the most effective adsorbent, a significant advantage over systems based on the natural rusting of zero-valent (i.e. metallic) iron. Design and cost tradeoffs with current density include the required power of an electricity source, which is based in part on operating current ${ }^{2}$, and the time required to achieve a certain dosage of EGA which is in turn related to treatment time.

Charge density is the amount of charge delivered per liter of water treated (in C/L). It is directly related to the amount of iron dissolved into solution, and therefore controls the dosage of EGA applied to the water. Cost tradeoffs include electricity and iron consumption, both of which increase linearly with charge density. The current density and charge density both depend on the operating current and are related to each other according to the following:

$$
q=j T_{c p}(A / V)
$$

where $q$ is the charge density, $j$ is the current density, $T_{c p}$ is the current processing time (i.e. the amount of time that current flows between the electrodes), and $A / V$ is the ratio between the active electrode surface area and the solution volume in the electrochemical cell.

Several researchers have looked at the effect of current density and charge density on removal efficiency in electrocoagulation. Chen et al. (2000) reported no effect of current density on oil and grease removal ( $\mathrm{pH} 2.4$, typical of wastewaters). Kumar et al. (2004) similarly reported no effect on arsenic removal efficiency within a range of $\mathrm{j}=0.65-1.53 \mathrm{~mA} / \mathrm{cm}^{\wedge} 2(\mathrm{pH} \mathrm{6-8})$. Both Chen et al. (2000) and Kumar et al. (2004) named charge density as the major factor determining removal efficiency in electrocoagulation.

Several ions common in groundwaters, such as bicarbonate, phosphate, and silicate, have been known to decrease the arsenic removal capacity of iron-based adsorbents (Meng et al., 2000). These ions are found in abundance in the groundwaters of Bangladesh (BGS, 2001). However, to the authors' knowledge, prior to this work the parameters of electrocoagulation have not been systematically tested in the groundwater environment of Bangladesh.

\subsection{Methods}

Synthetic Bangladesh groundwater: Batch experiments were performed with synthetic, arsenic-spiked groundwater designed to mimic the main characteristics of Bangladesh groundwater according to the British Geological Survey (BGS, 2001). The average arsenic concentration of prepared batches was $560+/-30 \mathrm{ppb}$, of which 290 +/- $20 \mathrm{ppb}$ is As(III). The total composition is shown in Table 1.

Table 1: Composition of synthetic Bangladesh groundwater. Note that $1 \mu \mathrm{g} / \mathrm{L}=1 \mathrm{ppb}$.

\begin{tabular}{|c|c|c|c|c|c|c|c|c|c|c|}
\hline $\begin{array}{c}\mathrm{P} \\
(\mathrm{mg} / \mathrm{L})\end{array}$ & $\begin{array}{c}\mathrm{Si} \\
(\mathrm{mg} / \mathrm{L})\end{array}$ & $\begin{array}{c}\mathrm{SO}_{4}{ }^{2-} \\
(\mathrm{mg} / \mathrm{L})\end{array}$ & $\begin{array}{c}\mathrm{Ca} \\
(\mathrm{mg} / \mathrm{L})\end{array}$ & $\begin{array}{c}\mathrm{Mg} \\
(\mathrm{mg} / \mathrm{L})\end{array}$ & $\begin{array}{c}\mathrm{Cl} \\
(\mathrm{mg} / \mathrm{L})\end{array}$ & $\begin{array}{c}\mathrm{Na} \\
(\mathrm{mg} / \mathrm{L})\end{array}$ & $\begin{array}{c}\mathrm{HCO}_{3}^{-} \\
(\mathrm{mg} / \mathrm{L})\end{array}$ & $\mathrm{pH}$ & $\begin{array}{c}\mathrm{As}_{\mathrm{TOT}} \\
(\mu \mathrm{g} / \mathrm{L})\end{array}$ & $\begin{array}{c}\mathrm{As}(\mathrm{III}) \\
(\mu \mathrm{g} / \mathrm{L})\end{array}$ \\
\hline 1.3 & 19.5 & 8 & 61 & 8 & 125 & 138 & 275 & $7.0 \pm 0.2$ & $560 \pm 30$ & $290 \pm 20$ \\
\hline
\end{tabular}

\footnotetext{
${ }^{2}$ This is not a direct tradeoff since the surface area of electrode may be manipulated within practical constraints to change the current density without increasing the operating current.
} 
Batch Experiments using synthetic groundwater: Batch experiments were performed in an electrochemical cell using an iron anode and copper electrode. Contaminated water was treated in 3liter batches using a galvanostatic current. Treated solution was stirred for an additional 60 minutes with no electrodes. All tests were duplicated and the results averaged.

Batch tests using real Bangladesh groundwater: Groundwater samples were obtained from several arsenic contaminated tube wells in rural villages of Jhikargachha, Abhaynagar, and Sonargaon Upazilas in Bangladesh. One liter of water from each well was collected after approximately 5 minutes of pumping (to avoid bacterial contamination and oxygenated water in the well head) and stored in tightly capped polyethylene bottles filled to the brim. Sample bottles were stored in a cool dark place (to avoid algae growth and photo-oxidation) for approximately two weeks before testing ${ }^{3}$. Initial arsenic concentrations at the time of collection ranged from 350- $700 \mathrm{ppb}$, however concentrations measured immediately before treatment were $100-500 \mathrm{ppb}$. This is likely due to arsenic complexation with naturally precipitating iron compounds already present in the groundwater. Indeed, a brown precipitate (characteristic of iron hydroxides) appeared in the samples a few hours after collection. Arsenic removal capacity was assessed with respect to the arsenic concentration immediately before treatment. The applied charge density was double or more the charge density required to remove equivalent amounts of arsenic in synthetic groundwater. The treatment process was similar to that described above, with the exception of an older cell design that physically separated the cathode from the anode using a Schott porous glass frit filter. Internal tests showed no difference in arsenic removal between the two cell designs.

Chemical Analysis: Aqueous arsenic concentrations were determined by inductively coupled plasma (ICP) mass spectroscopy (Curtis \& Tompkins, Ltd Analytical Laboratory, Berkeley, CA) with a reported accuracy of $10 \%$. The background concentration of arsenic in our deionized water was found to be negligible.

\subsection{Results}

\subsubsection{Batch tests in synthetic Bangladesh groundwater}

Synthetic Bangladesh groundwater spiked with $300 \mathrm{ppb}$ As(III) and $300 \mathrm{ppb} \mathrm{As}(\mathrm{V})$ was treated at current densities $J=0.02,1.1$ and $5.0 \mathrm{~mA} / \mathrm{cm}^{2}$. Figure 1 shows that the arsenic concentration in each case was reduced to the WHO limit or below after passing a charge density of $q=25,150$, and 175 $\mathrm{C} / \mathrm{L}$ respectively. Contrary to the results of Kumar et al. (2004) and Chen at al. (2000), Figure 1 shows a clear distinction in removal capacity (in ppb-removed per coulomb) with current density. In fact, treatment at current density $0.02 \mathrm{~mA} / \mathrm{cm}^{2}$ appears to have a removal capacity six times higher than treatment at $1.1 \mathrm{~mA} / \mathrm{cm}^{2}$ - a significant increase. This discrepancy with Kumar et al. (2004) could be due to the narrow range of current densities probed by the group $\left(J=0.65-1.53 \mathrm{~mA} / \mathrm{cm}^{2}\right)$. Because the current density is expected to affect the composition of the adsorbent, the removal capacity is likely to be constant over certain ranges of current density (with roughly the same composition), rather than a continuous function of current density. In addition, these ranges would be specific to the contaminant

\footnotetext{
${ }^{3}$ Note that a lag time between water collection and testing is very undesirable due to chemical changes that can occur during storage. In this case, a delay was unavoidable due to a lack of adequate testing facilities in the field.
} 
in question. The general findings of Chen et al. (2000), who used oil and grease, could be irrelevant in this case.

The discrepancy could also be due to some influence of current processing time, $T_{c p}$, which is independent of charge density. $T_{c p}$ affects certain electrochemical processes that can affect arsenic removal, such as electrochemical oxidation of As(III) and coagulation enhanced by the electric field. This potential effect is a subject of ongoing research.

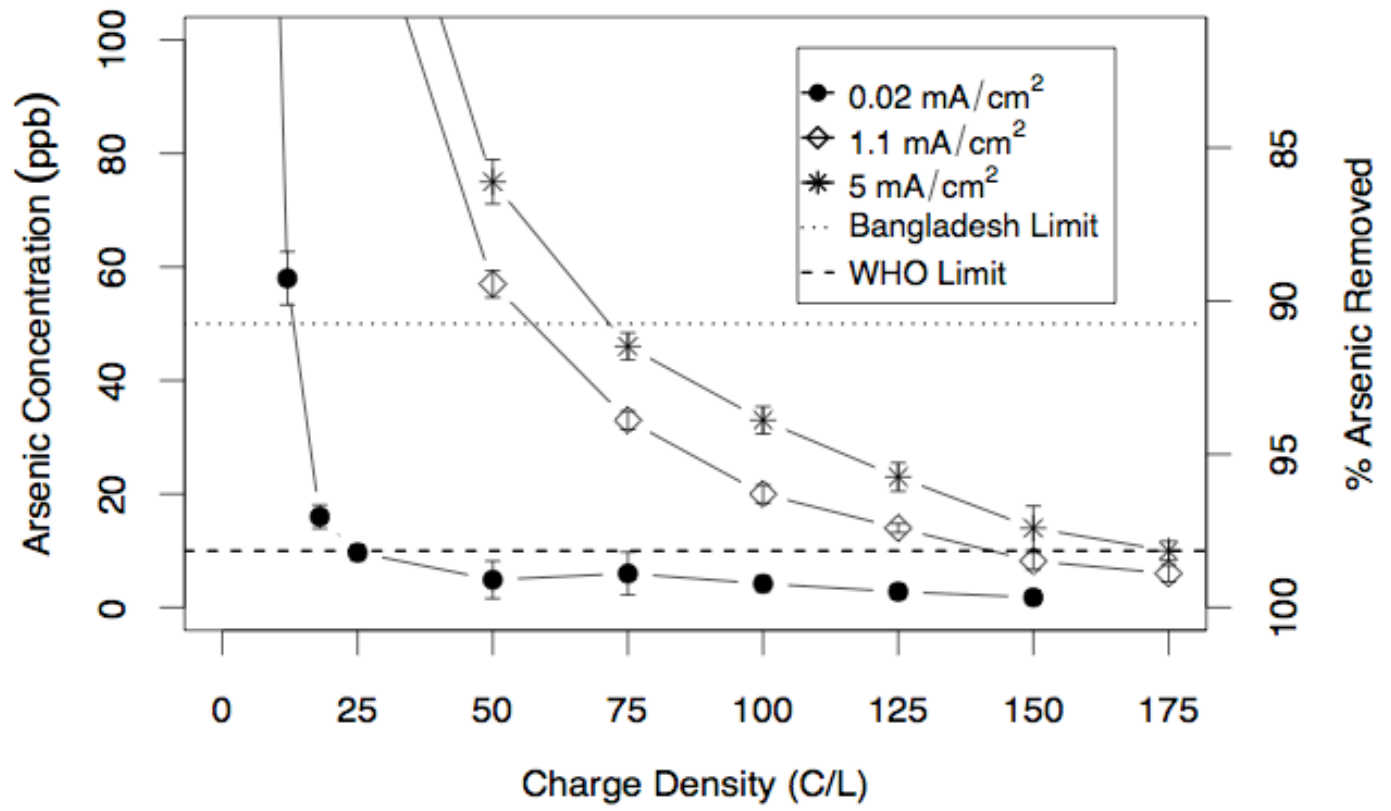

Figure 1: Arsenic concentration (left axis) and percent arsenic removed (right axis) as a function of charge density after ECAR treatment of synthetic Bangladesh groundwater operated at three different current densities. Initial arsenic concentration was 540 ppb (the y-axis above is scaled down to show detail near the WHO limit of 10 ppb). The WHO recommended limit (10 ppb) and legal Bangladesh limit (50 ppb) are shown as dashed and dotted lines respectively.

These results suggest that current density and charge density are both important parameters governing the performance of ECAR treatment in Bangladesh groundwater. It is worthwhile to note that some or all of the changes in removal capacity at different current densities may be due to background electrochemical processes, such as oxygen evolution, that may become more prevalent at higher current densities. In this case, the composition of EGA may not change, but the diversion of electrons to alternate processes would diminish the amount of iron dissolved into the water relative to lower current densities, thereby diminishing the amount of arsenic removed. Causes for the observed trends are being investigated currently.

\subsubsection{Batch tests using real Bangladesh groundwater}

In addition to synthetic Bangladesh groundwater, ECAR was used to treat real arsenic-contaminated groundwater from three sub-districts of Bangladesh, including Jhikargachha, Abhaynagar, and Sonargaon. Pre- and post- treatment arsenic concentrations are shown in Figure 2 for the tube well water as well as synthetic Bangladesh groundwater treated at the same time using the same electrochemical cell. Pre-treatment arsenic concentrations in the tube well samples ranged from 93 - 
$510 \mathrm{ppb}$. In Bangladesh, 96\% of tube wells with arsenic greater than $10 \mathrm{ppb}$ have arsenic less than 510 ppb (BGS, 2001). In every case, ECAR was able to reduce arsenic concentrations below the WHO recommended limit of $10 \mathrm{ppb}$.

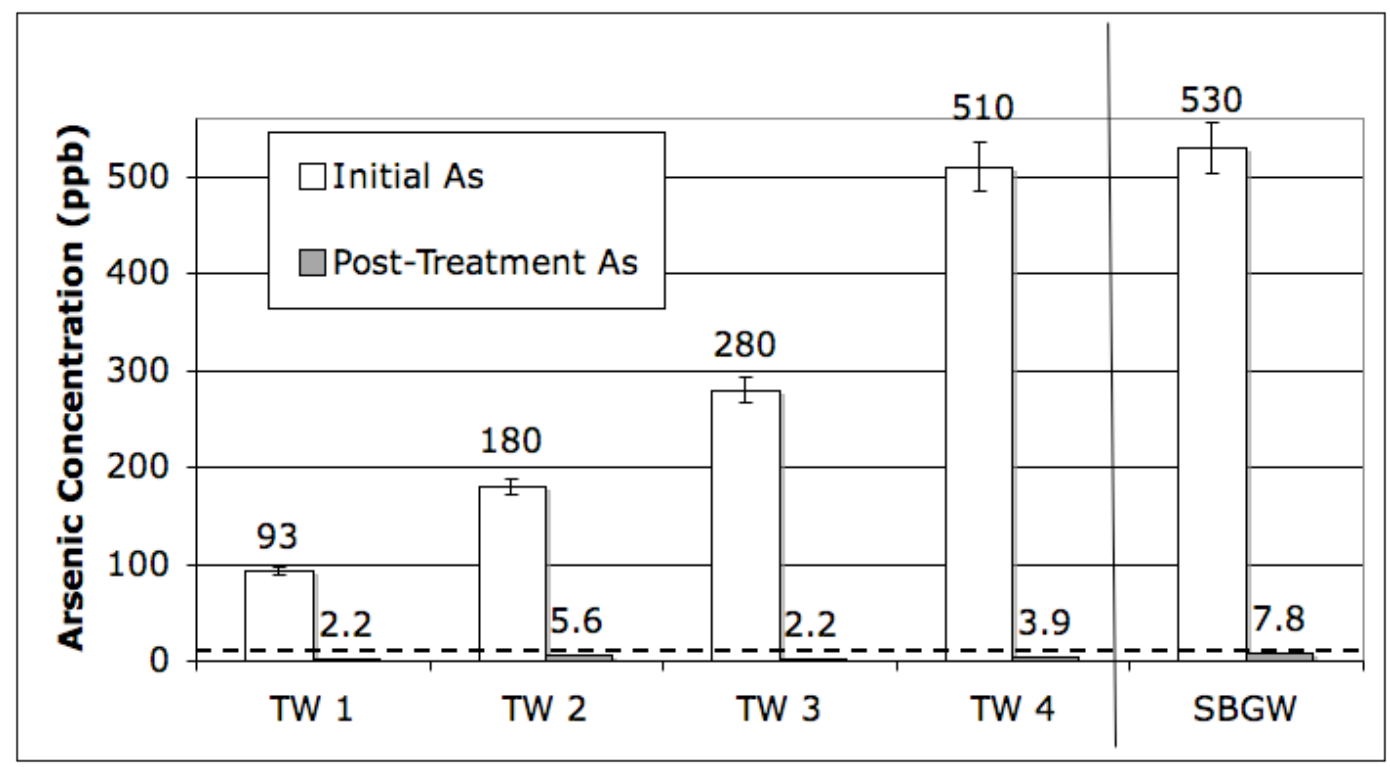

Figure 2: Initial and post-ECAR treatment arsenic concentrations for groundwater taken from four contaminated tube wells in Bangladesh (TW 1 - 4) along with synthetic Bangladesh groundwater (SBGW) for comparison. Tube well water was collected from villages in Jhikargachha, Abhaynagar, and Sonargaon Upazilas in Bangladesh. ECAR treatment conditions varied. The dashed line represents the WHO recommended limit (10 ppb).

\subsection{Operating costs and waste estimates}

Operating cost estimates are possible based on research results suggesting a dosage of $q=150 \mathrm{C} / \mathrm{L}$ at $J$ $=1.1 \mathrm{~mA} / \mathrm{cm}^{2}$ for Bangladesh groundwater. Exact operating conditions (current and voltage) will depend on the final electrode area and available voltage sources. However, if we assume a $12 \mathrm{~V}$ source (i.e. a car battery or photovoltaic system) and an operating current of $1 \mathrm{amp}$ (assuming a reasonable electrode area of $\sim 1000 \mathrm{~cm}^{2}$ ), we find that the power consumption per liter is $5 \cdot 10^{-4} \mathrm{kWh}$. Assuming the highest price scenario, and using US $\$ 0.50$ per $\mathrm{kWh}$ for photovoltaic electricity (PV) and 10 liters/person/day for drinking water, this amounts to $\$ 0.0025$ per person per day. Costs can be further reduced by tailoring the treatment to local water conditions, including the initial arsenic concentration and amount of bicarbonate, phosphate, and silicate present in the groundwater.

The cost of the iron electrode itself, the only consumable in the process, can be factored in. Passing $150 \mathrm{C} / \mathrm{L}$ dissolves $290 \mathrm{mg} \mathrm{Fe} /$ person/day (assuming all becomes $\mathrm{Fe}^{3+}$, and $10 \mathrm{~L} /$ person/day). Using the cost of iron nails in Bangladesh (US $\$ 4.40 / \mathrm{kg}$ ) this adds about $\$ 0.0013 /$ person/day to the cost of ECAR treatment, meaning the total cost of operation with PV (including consumables) is $\$ 0.0038$ per person per day, well below US $1 \notin$.The total cost per household per year (assuming a 6 person household) is US $\$ 8.32$.

In the ECAR process, arsenic-laden EGA sludge is separated from potable water and must be disposed. During lab tests, the sludge produced from treatment at $150 \mathrm{C} / \mathrm{L}$ extrapolated to 10 liters per person per day amounts to only 120 grams/person/year. This is significantly less than the waste produced by many point-of-use household filters. 


\section{Technology Implementation}

The most common implementation scheme for arsenic treatment in Bangladesh is the distribution of household filters containing a low cost arsenic adsorbent. A household implementation scheme requires each family to properly maintain a filter system. This requirement leads to a number of undesirable results. Filter maintenance is time consuming, and high abandonment rates of household filter systems are attributed in large part to the amount of maintenance and attention required (Ahmad et al., 2003). In addition, households have no ability to monitor arsenic concentrations and thus no feedback to determine when maintenance or replacement is required, meaning that some households making every attempt to treat their water may still be drinking arsenic-contaminated water. The lack of monitoring capability also adds to inefficiency of arsenic removal, since adsorbent dosages must be overestimated to cover the highest possible arsenic concentrations and harshest possible composition of ions that compete with arsenic for adsorbent sites. Finally, household systems limit the available technologies to those that can be powered in a rural area, usually omitting highly efficient technologies that require electricity.

An alternative to household implementation is a community clean water center with full cost recovery. This means that clean water would be sold at an affordable price from a central community location. Studies have shown a strong preference for community scale treatment over household filters (Ahmad et al., 2003). A community center is advantageous because it (1) removes the burden of maintenance from the households, (2) allows for centralized monitoring of water quality, both ensuring that the treated water continues to be safe and allowing treatment to be tailored to local water conditions, lowering costs and waste, and (3) allows for rapid upgrades as new safer or lower cost technology is developed. A community system operating under full cost recovery is key to providing sustainable water treatment over time. A modest profit would provide an incentive for local stakeholders to efficiently maintain the system, tailor the technology to local conditions, monitor water quality, and upgrade the technology as appropriate. Importantly, it would also allow Bangladeshis to reap the benefits of electric technologies such as ECAR.

ECAR technology is very compatible with a community clean water center operating under full cost recovery. Operating costs, including electricity and consumable iron, are estimated to be very low ( $\$ 0.0038 /$ person/day or $\$ 8.32 /$ household/year; see above). Waste produced is very low (120 grams/person/year). The iron required is very low, reducing the need for a continuous supply chain (the full amount of iron need for a center serving 6000 people is only $635 \mathrm{~kg}$ per year, which could be supplied in a single shipment). The constant current circuitry required is simple, robust, and readily available. Electrochemical cleaning of the electrodes can be achieved by switching the current direction once per day (avoiding the use of toxic or corrosive regeneration chemicals). ECAR technology is scalable. Finally, initial tests (presented above) show that ECAR is very effective at reducing high levels (500-600 ppb) of arsenic in Bangladesh groundwater, including both As(V) and As(III), to below the WHO recommended maximum limit of $10 \mathrm{ppb}$.

\section{Policy Implications}

The community clean water center with full cost recovery model has been successfully implemented in India through the use of public-private partnerships (PPP). WaterHealth International ${ }^{4}$ (Irvine, CA)

\footnotetext{
${ }^{4}$ www.waterhealth.com
} 
provides clean drinking water to more than a million people in rural Indian villages through publiclyowned, privately-managed village-scale water treatment centers. For WaterHealth, the PPP is a partnership between a local financial institution, a local NGO, a private company constructing and maintaining the treatment center, and the local village government. Users pay a small fee $(\sim 2.5$ US cents per 10 liters) to collect clean water from the treatment center, covering the capital and operating costs as well as a modest profit. Participation by the financial institution allows for low upfront costs to the village. The center is paid off over 8 years.

The PPP model is an innovative way to balance the tradeoffs between public and private water treatment. Community participation is encouraged through the partnership with the local government and liaison activities provided by the local NGO. The ability to retain a modest profit encourages tailoring services to the local conditions and demands ${ }^{5}$, as well as using new technologies to cut costs without sacrificing water quality. Water quality monitoring and affordability can be enforced by local government ownership of the treatment center. Policy should encourage and incentivize these partnerships to allow for rapid scale-up of clean water provision throughout Bangladesh.

\section{Next Steps - Field Testing a Prototype}

A small-scale continuous flow prototype device based on ECAR technology has been built (Figure 3). The prototype was found to successfully reduce $600 \mathrm{ppb}$ As to below the WHO limit in synthetic Bangladesh groundwater (data to be published at a later date). The prototype was recently operated in Bangladesh and arsenic-contaminated region of Cambodia, achieving very promising results. It is currently being prepared for more rigorous field-testing in Bangladesh.

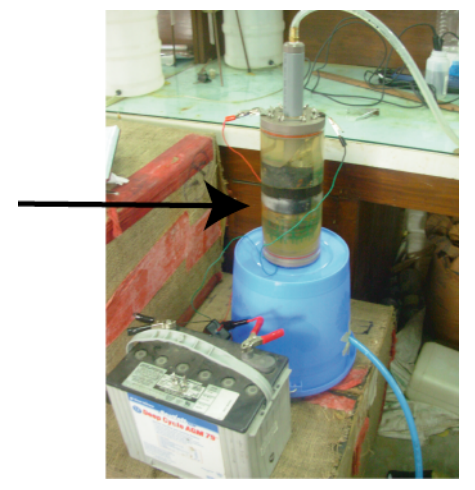

Figure 3: ECAR prototype device (shown by arrow) being tested at Bangladesh University of Engineering and Technology (BUET), in Dhaka, Bangladesh. Notice the $12 \mathrm{~V}$ car battery - in the field, batteries could be coupled with solar photovoltaic panels.

\section{Conclusions}

Electrochemical arsenic remediation (ECAR) has been successfully tested in synthetic Bangladesh water and found capable of reducing $600 \mathrm{ppb}$ As (including $300 \mathrm{ppb}$ As(III)) to below the WHO recommended limit of $10 \mathrm{ppb}$. The effect of current density and change density has been explored and

\footnotetext{
${ }^{5}$ WaterHealth has found that the sale price of water is cheap enough to enable local entrepreneurs to make a profit delivering water to the users door - mitigating the inconvenience of having to walk to the community center.
} 
each has been found to affect arsenic removal capacity in some way. In general, it was found that removal capacity increased in the order of $j=0.02 \mathrm{~mA} / \mathrm{cm}^{2}>1.1 \mathrm{~mA} / \mathrm{cm}^{2}>5.0 \mathrm{~mA} / \mathrm{cm}^{2}$, though further exploration of the independent effect of current processing time is needed. The charge density requirements to reach the WHO limit vary with current density. The most viable conditions tested (based on a treatment time $<3$ hours) were $j=1.1 \mathrm{~mA} / \mathrm{cm}^{2}$ and $q=150 \mathrm{C} / \mathrm{L}$.

ECAR treatment has been used to treat real Bangladesh groundwater with initial arsenic concentrations between 93 - 510 ppb. In all cases, ECAR was able to reduce arsenic levels to below the WHO limit.

In light of the failure to achieve widespread adoption of household filters in Bangladesh, we propose a community clean water centers with full cost recovery. This not only improves upon the household model, but also makes electricity-based technology viable in potentially non-electrified rural areas. ECAR technology is very compatible with this model due to its low estimated operating cost (\$0.0038/person/day including a PV electricity supply and consumable iron), low waste output (120 grams/person/year), easy maintenance that requires no strong alkalies or corrosive acids, limited supply chain needs, and scalability. Public-private partnerships (PPP) should be encouraged by policy to ensure sustainable operation and rapid scale up of community clean water centers.

\section{Acknowledgements}

This work was partly supported by the Director, Office of Science, of the U.S. Department of Energy under Contract No. DE-AC02-05CH11231. We would like to thank our many funders: LBNL's Laboratory Director's Research and Development (LDRD) Program, the UC Berkeley Blum Center for Developing Economies, the USEPA P3 award, the UC Berkeley Bears Breaking Boundaries Contest, the UC Berkeley Sustainable Products and Solutions Program, and UC Berkeley Big Ideas Marketplace. We would also like to thank Lawrence Berkeley National Laboratory, which is where the bulk of our preliminary research has occurred. Thanks to the Berkeley Arsenic Alleviation Group (BAAG), especially Johanna Mathieu, for valuable collaboration and advice. Thanks to Iqbal and Kamal Quadir who provided us funds and support for our first trip to Bangladesh.

\section{References}

Ahmad, J., Goldar, B.N., Misra, S. and Jakariya, M., 2003. "Willingness to pay for arsenic-free, safe drinking water in Bangladesh." New Delhi, India: Water and Sanitation Programme-South Asia, The World Bank.

Balasubramanian, N. and Madhavan, K., 2001. "Arsenic removal from industrial effluent through electrocoagulation." Chemical Engineering \& Technology, 24(5): 519-521.

Beck, R., 2007. "World facing arsenic timebomb." BBC News: http://news.bbc.co.uk/2/hi/science/nature/6968574.stm.

BGS, 2001. "Arsenic contamination of groundwater in Bangladesh." WC/00/19, British Geological Survey, Keyworth.

Bhattacharya, P., Jacks, G., Ahmed, K.M., Routh, J. and Khan, A.A., 2002. "Arsenic in groundwater of the Bengal delta plain aquifers in Bangladesh." Bulletin of Environmental Contamination and Toxicology, 69(4): 538-545.

Chen, G., 2004. "Electrochemical technologies in wastewater treatment." Separation and Purification Technology, 38(1): 11-41.

Chen, X.M., Chen, G.H. and Yue, P.L., 2000. "Separation of pollutants from restaurant wastewater by electrocoagulation." Separation and Purification Technology, 19(1-2): 65-76. 
Chowdhury, U.K. et al., 2000. "Groundwater arsenic contamination in Bangladesh and West Bengal, India." Environmental Health Perspectives, 108(5): 393-397.

Hansen, H.K., Nunez, P. and Grandon, R., 2006. "Electrocoagulation as a remediation tool for wastewaters containing arsenic." Minerals Engineering, 19(5): 521-524.

Holt, P.K., Barton, G.W., Wark, M. and Mitchell, C.A., 2002. "A quantitative comparison between chemical dosing and electrocoagulation." Colloids and Surfaces A-Physicochemical and Engineering Aspects, 211(2-3): 233-248.

Hoque, B.A. et al., 2004. "Demand-based water options for arsenic mitigation: An experience from rural Bangladesh." Public Health, 118(1): 70-7.

Kahn, M., 2007. "Arsenic in water a risk to 140 million people." Reuters: http://www.alertnet.org/thenews/newsdesk/L29757483.htm.

Kumar, P.R., Chaudhari, S., Khilar, K.C. and Mahajan, S.P., 2004. "Removal of arsenic from water by electrocoagulation." Chemosphere, 55(9): 1245-1252.

Mameri, N. et al., 1998. "Defluoridation of septentrional sahara water of north Africa by electrocoagulation process using bipolar aluminium electrodes." Water Research, 32(5): 16041612.

Meng, X., Bang, S. and Korfiatis, G.P., 2000. "Effects of silicate, sulfate, and carbonate on arsenic removal by ferric chloride." Water Research, 34(4): 1255-1261.

Parga, J.R. et al., 2005. "Arsenic removal via electrocoagulation from heavy metal contaminated groundwater in La Comarca Lagunera Mexico." Journal of Hazardous Materials, 124(1-3): 247-254.

Pouet, M.F. and Grasmick, A., 1995. "Urban waste-water treatment by electrocoagulation and flotation." Water Science and Technology, 31(3-4): 275-283.

Rahman, M.M. et al., 2005. "The magnitude of arsenic contamination in groundwater and its health effects to the inhabitants of the Jalangi; one of the 85 arsenic affected blocks in West Bengal, India." Science of the Total Environment, 338(3): 189-200.

Smith, A.H., Lingas, E.O. and Rahman, M., 2000. "Contamination of drinking-water by arsenic in Bangladesh: A public health emergency." Bulletin of the World Health Organization, 78(9).

Vergara, S.E., 2007. "Why do POUs fail? Barriers to the adoption of point of use water treatment technologies." Masters Thesis, UC-Berkeley, Berkeley, CA, 94 pp.

Vlyssides, A.G., Papaioannou, D., Loizidoy, M., Karlis, P.K. and Zorpas, A.A., 2000. "Testing an electrochemical method for treatment of textile dye wastewater." Waste Management, 20(7): 569-574.

Yu, W.H., 2003. "Socio-hydrologic approaches for managing groundwater contamination problems: Strategies for the arsenic problem in Bangladesh." Harvard University, Cambridge, Massachusetts, $323 \mathrm{pp}$. 